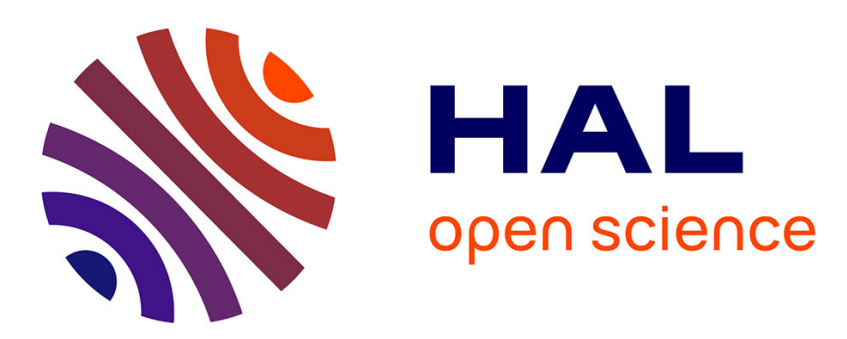

\title{
The price effects of monetary shocks in a network economy
}

Antoine Mandel, Davoud Taghawi-Nejad, Vipin Veetil

\section{To cite this version:}

Antoine Mandel, Davoud Taghawi-Nejad, Vipin Veetil. The price effects of monetary shocks in a network economy. Journal of Economic Behavior and Organization, 2019, 164, pp.300-316. 10.1016/j.jebo.2019.06.009 . halshs-02334593

\section{HAL Id: halshs-02334593 \\ https://shs.hal.science/halshs-02334593}

Submitted on 25 Oct 2021

HAL is a multi-disciplinary open access archive for the deposit and dissemination of scientific research documents, whether they are published or not. The documents may come from teaching and research institutions in France or abroad, or from public or private research centers.
L'archive ouverte pluridisciplinaire HAL, est destinée au dépôt et à la diffusion de documents scientifiques de niveau recherche, publiés ou non, émanant des établissements d'enseignement et de recherche français ou étrangers, des laboratoires publics ou privés.

\section{다)(1) $(5$}

Distributed under a Creative Commons Attribution - NonCommercial| 4.0 International 
Version of Record: https://www.sciencedirect.com/science/article/pii/S0167268119301994 Manuscript_81a5fa04c43db5fe3f6d12b405d335da

\title{
The Price Effects of Monetary Shocks in a Network Economy*
}

\author{
Antoine Mandel ${ }^{\dagger} \quad$ Davoud Taghawi-Nejad ${ }^{\ddagger} \quad$ Vipin P. Veetil ${ }^{\S}$ \\ June 10, 2019
}

\begin{abstract}
Empirical evidence shows monetary shocks have two temporary effects on the distribution of prices. One, the dispersion of cross-section of prices increases in response to monetary shocks. Two, some prices change in the 'wrong' direction: some prices decrease in response to positive monetary shocks, and increase in response to negative monetary shocks. We present a model that generates the two effects of monetary shocks on the distribution of prices as an out-of-equilibrium phenomena. Firms are related to each other through a production network. Monetary shocks change the working capital of a subset of firms and percolate to other firms through buyer-seller linkages. Price dispersion increases because the percolation of a monetary shock through the production network causes prices to differentially deviate from their steady state values. Some prices change in the wrong direction because a shift in one firm's demand causes a shift in another firm's supply (and vice-versa), thereby generating complicated chains of bi-directional price changes. Monetary shocks can significantly disturb relative prices even when all prices are fully flexible.
\end{abstract}

JEL Classification C63, C67, D80, E31, E52.

Key Words Prices, Money, Networks, Monetary Shocks, Agent-based Model, Out-of-equilibrium Dynamics.

\footnotetext{
${ }^{*}$ Antoine Mandel and Vipin P. Veetil acknowledge support from the Horizon 2020 research and innovation programme under grant agreement No. 640772 (DOLFINS) and from the European Union 7th framework programme under grant agreement No. 603416 (IMPRESSIONS).

${ }^{\dagger}$ Paris School of Economics, Université Paris 1 Panthéon-Sorbonne. Maison des Sciences Économiques, 106-112 Boulevard de l'hôpital 75647 Paris Cedex 13, France.

¥Institute for New Economic Thinking, Eagle House, 6EA, Walton Well Rd, Oxford OX2 6ED, Oxford University, United Kingdom.

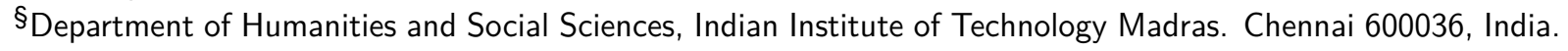




\section{Introduction}

Empirical evidence suggests monetary shocks have two temporary effects on the distribution of prices. The first effect is an increase in the dispersion of cross-section of prices (Bils \& Klenow 2004). The second effect is wrong directional price changes: some prices decrease in response to positive monetary shocks and increase in response to negative monetary shocks: Lastrapes (2006) and Balke \& Wynne (2007) report approximately 50\% of commodity prices change in the wrong direction. Although sticky price models address the increase in price dispersion (Calvo 1983, Mankiw \& Reis 2002, Sims 2003), the origin of wrong directional price changes remains unexplained. The problem is of significance because relative price deviation is the way in which monetary policy affects real economic activity, at least in a world where agents' demand and supply curves are homogeneous of degree zero with respect to prices (Friedman 1977).

In this paper, we argue that these two empirical regularities can be jointly explained as a disequilibrium phenomena that emerges during the propagation of monetary shocks through the production network of an economy. Furthermore, we show that the topology of the production network influences the transmission of monetary shocks to the real economy. More specifically, the greater the mean degree of a scale-free production network, the less pronounced the price effects of the monetary shocks. Our analysis relies on an out-of-equilibrium extension of Acemoglu et al.'s (2012) network economy model developed by Gualdi \& Mandel (2016). We study monetary shocks whose initial impact upon agents is heterogeneous. Monetary shocks take the form of an increase in the working capital of a subset of firms much like in Anthonisen (2010). The firms which experience an increase in working capital increase the demand for inputs and thereby transfer new money to their suppliers. The suppliers in turn increase the demand for their respective inputs and transfer money to other firms. New money percolates in the economy through demand-supply linkages in the production network. In the short run, price dispersion increases because the percolation of money through the production network draws prices away from their steady state values to different degrees. Some prices deviate further from their steady state values than others because some firms experience greater transient changes in their demand or supply. Similarly, a negative monetary shock - a decrease in the working capital of a subset of firms-generates an increase in price dispersion because monetary changes percolate through the production network. In contradistinction to most models of monetary non-neutrality, within our model monetary shocks temporarily increase price dispersion though prices are fully flexible.

In response to a monetary shock not only do prices deviate from their pre-shock steady state values, but some deviate in the wrong direction. In other words, some firms decrease prices in response to a positive monetary shock (and some firms increase prices in response to a negative monetary shock). The propagation of a monetary shock through the production network is experienced by firms as supply shocks (changes in the prices of their inputs or the availability of working capital) and demand shocks (changes in the demand for their output). The propagation of a positive monetary shock can generate positive supply shocks and negative demand shocks for some firms at different time steps, thereby prodding these firms to decrease prices. For instance, the time sequence of monetary flows through the production network, induced by a monetary shock, can be such that some firms expand output due to the greater availability of working capital but do not encounter compensating increases in demand. Such firms decrease prices. Other firms may decrease prices because of decreases in the prices of some inputs, which itself may have happened because the suppliers of these inputs were able to expand output due to a fortuitous 
position in the production network (amidst money flows induced by a monetary shock). Supply side forces pertaining to the availability of working capital and prices of inputs are accompanied by demand side forces in generating wrong directional price changes, simply because one firm's supply is another firm's demand within a production network.

The positions of firms which first respond to a monetary shock and the buyer-seller relations between firms on the network determine the directions, magnitudes, and time sequences of changes in prices. The magnitude of wrong directional price changes from one time step to another can be large enough to take some prices below their pre-shock steady state value in response to a positive monetary shock. In the long run, price dispersion returns to its steady state level as monetary changes complete their percolation through the network and the economy reverts to a new equilibrium in which all prices have changed equiproportionally to the aggregate monetary shock.

Our analysis shows that the topology of the production network plays a role in determining the price effects of monetary shocks. Several authors have documented that real world production networks are scale-free to some extent (Atalay et al. 2011, Konno 2009). We find that the mean degree of the scale-free network influences both the increase in price dispersion and the wrong directional changes in prices in response monetary shocks (see section 4.3.4). Furthermore, there are significant differences between scale-free networks and balanced networks (regular graphs) when the initial impact of monetary shocks falls up all agents albeit differentially (see section 4.4.2). The topology of the production network therefore is a determinant of the transmission of monetary shocks to the real sector via its influence on relative prices.

Two assumptions of our model are pivotal in jointly generating increases in price dispersion and wrong directional price changes. The first assumption is monetary shocks are heterogeneous in their initial impact on agents (Christiano \& Eichenbaum 1995). To understand the significance of the first assumption note that within our model an equiproportional change in the working capital of all agents generates no change in the distribution of relative prices: all prices change instantaneously and equiproportionally with the same sign as the monetary shock. The second assumption is firms respond to changes in working capital by changing production decisions, which thereby generates the percolation of a monetary shock via the demand-supply linkages in the production network. To understand the significance of the second assumption note that monetary shocks will not percolate through the economy if firms production decisions do not depend on their working capital.

There is empirical and theoretical work to support both assumptions. The heterogeneous impact of monetary shocks on firms is well documented (Gertler \& Gilchrist 1994, lyer et al. 2013, CarbóValverde, Rodríguez-Fernández \& Udell 2016). The origins of the heterogeneous initial impact of monetary shocks may be viewed through Marshall's scissors. On the supply side of new money, monetary shocks are transmitted from the central bank to the banking system, and from the banking system to the real sector (Williamson 2008). Each of these transmissions works through a network of institutional arrangements which guide the flow of new money (Bikhchandani \& Huang 1993, White 1999). Empirical work finds monetary shocks have a heterogeneous impact on banks (Kashyap \& Stein 2000, Adrian \& Shin 2009). And banks have somewhat long term lending relationships with firms (De Masi et al. 2011, Beck et al. 2017). Banks may thus pass the heterogeneous impact of monetary shocks to firms through banks-firms networks (Delli Gatti et al. 2010). New money flows from the central bank into the economic organism through certain channels, and these channels do not branch homogeneously into the pockets of economic actors 
(Andrei, Herskovi \& Ledoit 2017). So much for the origin of heterogeneity on the supply side. On the demand side of new money, monetary shocks affect firms heterogeneously because of their differing positions with respect to a variety of factors including their demands for credit (Greenwald \& Stiglitz 1993, Holmstrom \& Tirole 1997, Gornemann, Kuester \& Nakajima 2012, Coibion et al. 2017). Firms with little access to internal sources of funding may be the first to avail new credit which becomes accessible with a positive monetary shock.

Our second assumption that firms respond to changes in working capital with changes in production decisions too finds empirical and theoretical support. The belief that firms production decision depends on their working capital may appear somewhat odd at first glance. After all, in a Modigliani-Miller world firms liquidity positions do not matter because of the substitutability between liabilities. A variety of empirical evidence however shows firms respond to changes in the availability of working capital with changes in production decisions (Stiglitz 1988, HoltzEakin, Joulfaian \& Rosen 1994, Clementi \& Hopenhayn 2006, Manova 2012). The two critical assumptions of our model paper therefore have some grounding in empirical reality.

Our paper is organised as follows. Section 2 presents a brief review of the related literature and the origins of the ideas developed in the paper. Section 3 presents the dynamics of our model. Section 4 investigates the impacts of monetary shocks on price dynamics and highlights how the structure of the production network influences the propagation of monetary shocks in the economy. Section 5 offers concluding thoughts. The Appendix illustrates the basic dynamics of our model with a three firm economy ${ }^{1}$.

\section{Related literature}

There is ample empirical literature on the impact of monetary shocks which documents the temporary increase in price dispersion and wrong directional price changes. Evidence on the increase in the dispersion of cross-section of prices in response to monetary shocks is documented in a range of contrubutions, notably Belton, Cebula \& Nair-Reichert (2002), Bils, Klenow \& Kryvtsov (2003), Lastrapes (2006), Balke \& Wynne (2007), Bick \& Nautz (2008), Baumeister, Liu \& Mumtaz (2013), and Hammoudeh, Nguyen \& Sousa (2015). Wrong directional price changes are documented in Balke \& Wynne (2007), Lastrapes (2006), and Baumeister, Liu \& Mumtaz (2013). Balke \& Wynne (2007) use data on monthly changes in the components of commodities Producer Price Index (PPI). At the highest level of disaggregation (the eight digit level) the data contains 130 time series in 1959 to 1228 time series in 2001. Lastrapes (2006) uses data of 69 commodity price indexes with complete monthly observations from 1959:1 to 2003:10. Both Balke \& Wynne (2007) and Lastrapes (2006) find that approximately 50\% of commodity prices change in the wrong direction following a monetary shock.

Several economists have tried to explain the dynamic of prices which emerge from monetary shocks using the notion of price stickiness. Sheshinski \& Weiss (1977) and Calvo (1983) developed early models of staggered price adjustments in which price dispersion temporarily increases in response to monetary shocks. In these models, firms adjust prices at different rates because prices

\footnotetext{
${ }^{1}$ The paper presents the most relevant results. An Online Appendix presents a comprehensive analysis of sensitivity with respect to the model's parameters, and an extension of our model in which firms carry working capital reserves and inventory to dampen price movements. The Online Appendix is available online at end of the paper: https://ssrn.com/abstract=2882994.
} 
are sticky and the degree of stickiness varies across firms. Mankiw \& Reis (2002) developed a model in which some firms receive information about the price level more frequently than others, thereby producing heterogeneous price changes. Sims (2003) developed a model in which firms change prices at different rates because they receive information with different time lags. In essence Mankiw \& Reis (2002) and Sims (2003) endogenized heterogeneous stickiness of prices. Heterogeneous stickiness models however do not generate price changes in the wrong direction: all prices change in the same direction albeit at different rates.

Furthermore, micro price data appears to be in contradiction with the mechanism for price changes ingrained in heterogeneous price stickiness models. Presumably heterogeneous price stickiness models predict flexible-prices increase before sticky-prices in response to a positive monetary shock. Bils, Klenow \& Kryvtsov (2003) however find when goods are divided into fixed and flexible price baskets, the average price of flexible-price goods decreases in the two months following a positive monetary shock while the average price of fixed-price goods remains unchanged. Therefore, from an empirical point of view there is some motivation to develop models of money-price dynamics which do not hinge on firm-level price stickiness.

Instead of relying on firm-level price stickiness, we study how wrong directional price movements emerge from the propagation of monetary shocks through the input-output structure of the economy. This line of research was proposed by Balke \& Wynne's (2007, p. 35): "Perhaps combining heterogeneity in financial market frictions with an input-output structure may yield relative price movements in response to a monetary shock closer to those documented above". Within the theoretical literature, our paper is closely related to Anthonisen (2010), who developed the first explicit model of the transmission of monetary policy through an economic network. Anthonisen (2010) discusses some aspects of the changes in relative prices due to monetary shocks but does not explain wrong directional price changes. More broadly, our work is related to the recent literature that attempts to gain new insights on macro-economic issues from the bottom-up by using the structure of the production network as a key driver of macro-economic dynamics (Carvalho 2014). Notably, Acemoglu et al. (2012) investigates how the structure of the network determines the amplification of micro-economic shocks while Barrot \& Sauvagnat (2016) analyzes the propagation of these shocks. Bigio \& La'O (2016) and Ozdagli \& Weber (2017) investigate the impact of the economy's production structure on the macro-economic response to financial and monetary shocks respectively. Carvalho \& Voigtländer (2014) and Gualdi \& Mandel (2018) investigate the relationships between production structure and economic growth.

From an historical perspective, the origins of the ideas developed in the paper can be traced back to Cantillon and Mises. In his "Essay on the Nature of Commerce in General", Cantillon (1755) highlights the percolation of monetary shocks in the economy through buyer-seller relationships. Cantillon writes "If the increase of actual money comes from Mines of gold or silver in the State, the Owner of these Mines, the Adventurers, the Smelter, Refiners, and all the other workers will increase their expenses in proportion to their gains. They will consume in their households more Meat, Wine, or Beer than before, will accustom themselves to wear better cloths, finer line, to have better furnishes Houses and other choicer commodities. They will consequently give employment to several Mechanichs who had not so much to before and who for the same reason will increase their expenses [...]the demand for Meat, Wine, Wool, etc. being more intense than usual, will not fail to raise their prices. These high prices will determine the Farmers to employ more Land to produce them in another year: these same Farmers will profit by this rise of prices and will increase the expenditure of their Families like others." Cantillon however did not deduce from his 
analysis that monetary shocks can generate wrong directional price changes. This discovery was made at the dawn of the twentieth century by Ludwig von Mises. Mises (1953, p. 140) began his analysis of monetary shocks from the proposition that when a monetary expansion occurs, " the increased quantity of money is received in the first place by a limited number of economic agents only and not by all". Beginning with the heterogeneity proposition, Mises (1949, p. 410) analyzed the consequences of the flow of money through the buyer-seller relations induced by a monetary shock and deduced that some prices may fall in response to a positive monetary shock because they are in the "most part demanded by those groups whose interests are hurt by inflation." Mises therefore discovered positive monetary shocks can generate negative demand shocks for some firms and is thus a conceptual precursor of the present work. In the light of the discoveries of Cantillon and Mises, one may christen the increase in dispersion of prices in response to monetary shocks as the "Cantillon Effect" and wrong directional price changes as the "Mises Effect".

\section{The model}

We place ourselves in the framework of the network economy studied in Acemoglu et al. (2012). There is a finite set of monopolistically competitive firms and a representative household. We denote the set of firms (which is also the set of goods) by $N=\{1, \cdots, n\}$ and the representative household by the index 0 . The representative household supplies a constant quantity of labor $l$ (normalized to 1) and has preferences represented by a Cobb-Douglas utility function of the form.

$$
u\left(x_{1}, \cdots, x_{n}\right)=\prod_{i=1}^{n} x_{i}^{\beta_{i}}
$$

with $\sum_{i=1}^{n} \beta_{i}=1$ and $\beta_{i}>0$ for all $i \in N$.

The firms interact through a production network. More specifically, each firm $i$ has a production function $f_{i}: \mathbb{R}_{+}^{M} \rightarrow \mathbb{R}_{+}$of the form

$$
f_{i}\left(l_{i},\left(y_{i j}\right)_{j \in N}\right)=l_{i}^{\alpha}\left(\prod_{j \in N} y_{i j}^{a_{i j}}\right)^{(1-\alpha)}
$$

where $l_{i} \in \mathbb{R}_{+}$is the labor input, $y_{i j} \in \mathbb{R}_{+}$the input of good $j, \alpha$ is the share of labor and $a_{i j} \in \mathbb{R}_{+}$ is the non-labor share of firm $i$ 's production costs spent on the input from firm $j$. We thus assume $\sum_{j \in N} a_{i j}=1-\alpha$ for all $i \in N$. The matrix $A=\left(a_{i j}\right)_{i, j \in N} \in \mathbb{R}_{+}^{N \times N}$ is the weighted adjacency matrix of the production network of the economy, with $a_{i j}>0$ if and only if $j$ is a supplier of input to $i$. Let $y_{i j}$ denote the flow of goods from $j$ to $i$ if $a_{i j}>0$. This network characterizes the economy that one can thus denote by $\mathscr{E}(A)$. The general equilibrium of such an economy is then defined as follows.

Definition 1. A general equilibrium of the economy $\mathscr{E}(A)$ is a collection of prices $\left(\bar{p}_{1}, \ldots, \bar{p}_{n}\right) \in \mathbb{R}_{+}^{N}$, wage $\bar{p}_{0} \in \mathbb{R}_{+}$, production levels $\left(\bar{q}_{1}, \ldots, \bar{q}_{n}\right) \in \mathbb{R}_{+}^{N}$, consumption levels $\left(\bar{x}_{1}, \ldots, \bar{x}_{n}\right) \in \mathbb{R}_{+}^{N}$, labor $\left\{\bar{l}_{i}\right\}_{i \in N} \in \mathbb{R}_{+}^{N}$ and commodity flows $\left\{\bar{y}_{i j}\right\}_{i, j \in N} \in \mathbb{R}_{+}^{N \times N}$ such that: 
1. Markets clear, that is one has:

$$
\begin{array}{rlr}
\forall i \in N, \bar{q}_{i}=\bar{x}_{i}+\sum_{j=1}^{n} \bar{y}_{j i}, \forall i \in N & \text { (goods market) } \\
1=\sum_{i=1}^{n} \bar{l}_{i} \quad \text { (labor market) }
\end{array}
$$

2. The representative consumer maximizes utility, that is $\left(\bar{x}_{i}\right)_{i \in N}$ is a solution to

$$
\left\{\begin{array}{cc}
\max & u\left(x_{1}, \cdots, x_{n}\right) \\
\text { s.t } & \sum_{i=1}^{n} \bar{p}_{i} x_{i} \leq \bar{p}_{0}
\end{array}\right.
$$

3. Firms maximize profits, that is for all $i \in N,\left(\bar{q}_{i}, \bar{l}_{i},\left(\bar{y}_{i j}\right) \in \mathbb{R}_{+}^{N+2}\right.$ is a solution to

$$
\left\{\begin{array}{cc}
\max & \bar{p}_{i} q_{i}-\bar{p}_{0} l_{i}-\sum_{j \in N} \bar{p}_{j} y_{i j} \\
\text { s.t } & q_{i} \leq f_{i}\left(l_{i},\left(y_{i j}\right)_{j \in N}\right)
\end{array}\right.
$$

It is then straightforward to show (see for example the appendix to Acemoglu et al. (2012)) that this economy has a unique equilibrium. Following Gualdi \& Mandel (2016), we introduce decentralized out-of-equilibrium dynamics in this framework. We consider time is discrete and indexed by $t \in \mathbb{N}$. Each firm $i \in N$ is initially endowed with a random amount of working capital $w_{i}^{0} \in \mathbb{R}_{+}$ and a random amount of output $q_{i}^{0} \in \mathbb{R}_{+}$. All random amounts are drawn from a uniform $(0,1)$ distribution. Each agent then engages every period in a sequence of local interactions with its connections (buyers and sellers) in the production network. More specifically, the following sequence of events take place every period time step $t \in \mathbb{N}$ :

1. Agents determine nominal demand to their suppliers according to the network weights: the nominal demand of firm $i$ towards firm $j$ is $a_{i j} w_{i}^{t}$. The nominal demand of the household towards firm $j$ is given by $\beta_{j} w_{0}^{t}$. And the nominal demand of firm $i$ for labor is $\alpha w_{i}^{t}$.

2. Firm $j$ sets the price $p_{j}^{t} \in \mathbb{R}_{+}$at its "local" market-clearing value:

$$
p_{j}^{t}=\frac{\sum_{i \in N} a_{i j} w_{i}^{t}+\beta_{j} w_{0}^{t}}{q_{j}^{t-1}}
$$

The household sets market-clearing wage:

$$
p_{0}^{t}=\sum_{i \in N} \alpha w_{i}^{t}
$$

3. Goods flow proportionally to demand, that is for all $i, j \in N$ :

$$
y_{i j}^{t}=\frac{a_{i j} w_{i}^{t}}{p_{j}^{t}} \quad \text { (inputs allocation ) }
$$




$$
\begin{array}{lr}
x_{i}^{t}=\frac{\beta_{i} w_{0}^{t}}{p_{j}^{t}} & \text { (consumption allocation) } \\
l_{i}^{t}=\frac{w_{i}^{t}}{\sum_{j \in N} w_{j}^{t}} & \text { (labor allocation) }
\end{array}
$$

4. Working capitals are updated on the basis of revenues, for all $i \in N$ :

$$
w_{i}^{t+1}=\sum_{j \in N} a_{j i} w_{j}^{t}
$$

And the household's wealth $w_{0}^{t+1}$ is simply the wage $p_{0}^{t}$ because quantity of labor is normalized to one.

5. Firms produce their output for the next period (and labor supply is replenished to 1). Namely, for all $i \in N$ :

$$
q_{i}^{t}=f_{i}\left(l_{i}^{t}, y_{i j}^{t}\right)
$$

Note that the condition in Step (1) amounts to assuming firms are rational in the choice of input combinations as they minimise production costs. However, they are myopic in the sense that they do anticipate potential changes in their revenues nor the need for the adjustment of their own output price. In a similar sense, the market-clearing condition in Step (2) is local (and partial) as it does not anticipate agents' response to future prices ${ }^{2}$. More generally, three aspects of the dynamic setting of our model are worth noting. First, agents make decisions based on local information: agents decisions are based on prices of their inputs, price of their output, and their working capital. This aspect of the model dynamics is motivated by the view that the economy is a system of distributed decision-making where macro variable emerge from micro decisions based on local information (Hayek 1945, Hayek 1964, Schelling 1969, Axtell 2003, Wagner 2012). The second aspect of our model worth noting is that agents interact out-of-equilibrium. The dynamics are non-tatonnement, nothing forbids trades at out-of-equilibrium prices. In this sense, the dynamics of our model merges the literature on "networks \& macro" (Dupor 1999, Horvath

\footnotetext{
${ }^{2}$ Within a network economy firms are unlikely to be able to forecast the time path of the prices of their inputs and their output in response to a monetary shock. 'Unlikely' given the computational and informational requirements to execute such a forecasting procedure. Prices exhibit significant and bi-directional movements in response to a monetary shock. The time sequence of changes in prices depends on the initial distribution of monetary shocks among agents, the network of linkages between agents, and the responsiveness of different firms to changes in the prices of their inputs and output. In the United States there are more than six million firms connected to each other on a production network (Axtell 2001, Atalay et al. 2011). It would be a phenomenal task for each firm to acquire the information necessary to compute rational expectations about the time path of the prices which matter to them. And even if the necessary information is acquired, it may be difficult to compute rational expectation within reasonable time simply because of the size of the problem, especially given the difficulty of computing general equilibrium (Scarf 1973, Norman 1994, Deng, Papadimitriou \& Safra 2003). There is some evidence to suggest simple heuristics perform well in such complex economic environments and in certain circumstances even outperform decisions procedures that consider more information and involve more computation (Gigerenzer \& Gaissmaier 2011). However, these heuristic tend to vary across environments as they emerge within the context of the decision problems faced by agents, which is why they have come to be associated with the notion of "ecological rationality" (Gigerenzer \& Selten 2002). Little is known about how agents make decisions when faced with bi-directional changes in prices within a network setting.
} 
2000, Acemoglu et al. 2012) with the literature on "non-tatonnement \& disequilibrium macro" (Barro \& Grossman 1976, Korliras 1977, Muellbauer \& Portes 1978). Much like in the older generation of non-tatonnment macroeconomic models, quantity signals play a role in economic decisions (Varian 1977). Firms' decisions are based not only on relative prices but also on realized quantities of working capital at each time step. The third aspect of our model worth noting is that money is not neutral. Neutral money is the idea that "the money required to make indirect exchange possible has no influence on relative prices" (Hayek 1976, p. 87). The idea of neutral money goes back to Wicksell and is the backbone of monetary analysis which works with notions like the aggregate demand for money (Bilo 2018). Within our model, money is not neutral in the out-of-equilibrium phase because firms' production decisions depend on the availability of working capital.

As is standard in the agent-based literature (Axtell 2000, Arthur 2006, Borrill \& Tesfatsion 2011), we analyze the behaviour of the model via monte-carlo simulations ${ }^{3}$. We first investigate convergence of the model towards the underlying general equilibrium of the economy. As illustrated in Figure 1 the model has robust properties of convergence towards equilibrium. Although, relaxation time depends on the value of the exponent, we obtain convergence except in degenerate cases (i.e. when the share of labor tends towards 0 or 1 ). The Online Appendix presents convergence results of the model with variations in other parameters. In absence of monetary shocks, the model defines out-of-equilibrium dynamics with robust properties of convergence.

\footnotetext{
${ }^{3}$ The model is developed in object oriented programming language Python. The code is available at bitbucket.org/VipinVeetil/networkeconomy. The code is modular and contains comments. The results of the agent-based computational experiments can be replicated using the model code (Lucius 2017). All computational experiments can be run, data generated, data processed, and plots created with the execution of a single line in the terminal after downloading the code from the bitbucket repository as described in the readMe_cantillon file in the repository.
} 


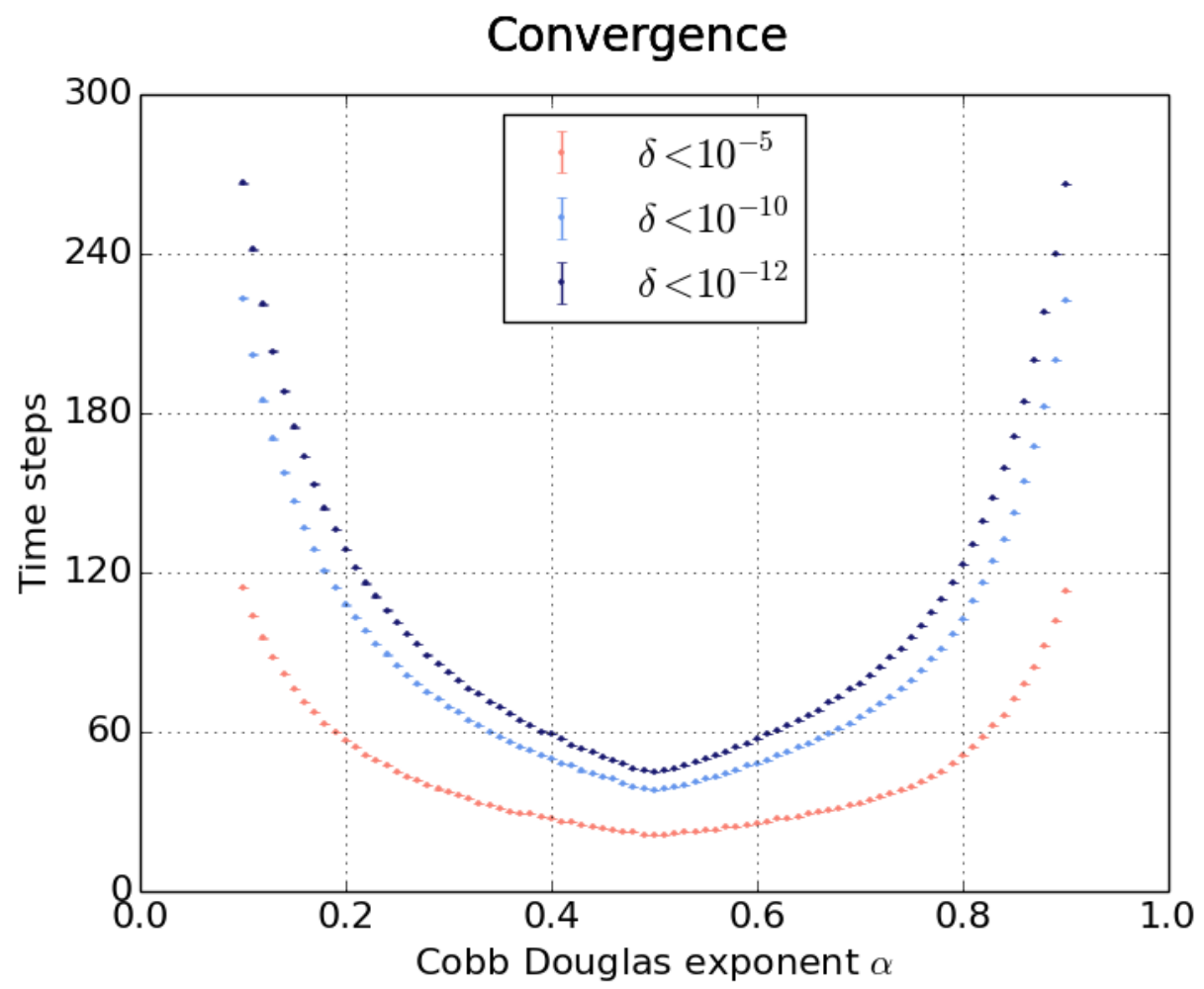

Figure 1: Number of time steps necessary for the economy to converge for different values of the Cobb Douglas exponent of the production function. Cobb Douglas exponent varies from 0.1 to 0.9 with increments of 0.01 . Figure presents the mean and standard error of 100 computational experiments for each value of the Cobb Douglas exponent. Convergence is measured by the mean absolute price change $\delta^{t}=\frac{1}{n} \sum_{i=1}^{n} \frac{\left|p_{i}^{t}-p_{i}^{t-1}\right|}{p_{i}^{t-1}}$.

\section{Impacts of monetary shocks}

\subsection{The experimental setup}

Following the insights of Cantillon and Mises as well as recent evidence on the heterogeneous impact of monetary shocks on firms (Gertler \& Gilchrist 1994, lyer et al. 2013, Carbó-Valverde, Rodríguez-Fernández \& Udell 2016), we study monetary shocks whose initial impact is on a subset of firms. A monetary shock is characterized by its size $s$ and homogeneity $g$. Size $s$ is specified as a proportion of the stock of money in the economy. And homogeneity $g$ is specified as the share of firms initially affected by a monetary shock shock. As $g$ increases from 0 to 1 the monetary shock becomes more homogeneous (or equivalently less heterogeneous). For instance, $s=0.01$ and $g=0.2$ means a monetary shock which increases the stock of money in the economy by $1 \%$ and initially affects $20 \%$ of the firms in the economy. The shocks are implemented in the following manner. We randomly select a share $g$ of the firms to initially receive an increase in working capital, denote these firms by set $F$. The increase in working capital of firm $i \in F$ is given by $\Delta w_{i}=\frac{w_{i}}{W} s M$ where $M$ is the total stock of money in the economy and $W$ the total stock of 
money held by the firms affected by the shock. In other words, the initial increase in working capital is such that all selected firms receive an equiproportional increase in working capital.

We ran about $10^{5}$ Monte-Carlo simulations to study the effects of monetary shocks on the distribution of prices with variations in several parameters including the size of the monetary shock $s$, the homogeneity of the monetary shock $g$, the mean degree of the production network $d$, number of firms in the economy $n$, and Cobb Douglas exponent of labor $\alpha$ (see Table 1 for the detailed setting of parameters). We ran these experiments both on scale-free and balanced (regular) production networks ${ }^{4}$. Scale-free networks are significant because the empirical buyerseller networks between firms is scale-free to some extent. Atalay et al. (2011) show the middle portion of the degree distribution of buyer-seller network of publicly traded firms in the US follows a power-law. And Konno (2009) show the degree distribution of the buyer-seller network between more than one million firms in Japan follows a power-law.

We also ran experiments with an alternate specification of the initial impact of monetary shocks, one in which the initial impact of a shock falls upon all agents albeit differentially (see section 4.4). And finally, we ran experiments with an extension of our model in which agents exhibit "smoothening behavior" by carrying inventory and working capital reserves to dampen changes in price and output (see Online Appendix).

Table 1: Parameters

\begin{tabular}{|c|l|c|l|c|}
\hline Parameter & Description & Bound & $\begin{array}{l}\text { Baseline } \\
\text { Value }\end{array}$ & Variation \\
\hline$\alpha$ & Cobb Douglas exponent & $(0,1)$ & 0.25 & {$[0.1,0.9]$} \\
\hline$d$ & Mean degree of the production network & $\mathbb{I}^{++}$ & 2 & {$[2,10]$} \\
\hline$n$ & Number of firms & $\mathbb{I}^{++}$ & 1000 & {$[1000,10000]$} \\
\hline$s$ & Size of monetary shock & $(0,1]$ & 0.01 & {$[0.01,0.10]$} \\
\hline$g$ & Homogeneity of monetary shock & $(0,1]$ & 0.1 & {$[0.01,1.0]$} \\
\hline
\end{tabular}

Our focus is the impact of monetary shocks on price dispersion on the one hand and on the distribution and the signs of price variations on the other hand. We measure price dispersion using the coefficient of variation of the cross section of normalised prices denoted by $v^{t}$ in period $t$ and

\footnotetext{
${ }^{4}$ We generate a new scale-free network for each computational experiment using Stanford Network Analysis Project's Python (Snapy) library. The Snapy function which generates a directional scale-free network takes two parameters: number of nodes ( $N$ firms) and mean degree of the distribution $(d)$. Snapy uses the Barabasi-Albert preferential attachment algorithm to generate a scale-free network (Barabási \& Albert 1999). The scale-free network generated by Snapy is non-directional. We transform it to a directional network with randomly assigning directions to links. We alter the network generate by Snapy in an insignificant manner to ensure all firms have a supplier of input and demander of output among other firms. Typically, less 1\% of the nodes in the Snapy network have either no incoming edges or no outgoing edges. To each of these nodes we assign a link to a randomly selected node, so that each node has at least one incoming link and one out going link. This allows each firm in our model to use at least one intermediate input to produce goods and sells its output to at least one firm. The exact buyer-seller linkages between firms on scale-free production networks varies across computational experiments because a new network is generated for each experiment.
} 
defined by:

$$
v^{t}:=\frac{\left.\sqrt{(} \sum_{i=1}^{m}\left(p_{i}^{t}-\hat{p}^{t}\right)^{2}\right)}{\hat{p}^{t}} \quad \text { where } \hat{p}^{t}=\frac{\sum_{i=1}^{m} p_{i}^{t}}{m} .
$$

We measure wrong-directional price changes by the proportion $\rho^{t}$ of prices below their pre-shock steady state values:

$$
\rho^{t}=\frac{1}{m} \sum_{i=1}^{m} I_{i}^{t} \quad \text { with } I_{i}^{t} \equiv \begin{cases}1 & \text { if } p_{i}^{t}<p_{i}^{*} \\ 0 & \text { otherwise }\end{cases}
$$

In what follows we report results from the dynamics induced by a positive monetary shock. Results pertaining to a negative monetary shock are symmetric and reported in the Online Appendix. We first demonstrate how increased price dispersion and wrong-directional price changes emerge from the model (subsection 4.2) and then investigate the sensitivity of these results to changes in structural parameters of the model (subsections 4.3 and 4.4 ).

\subsection{Basic Results}

Our first result is that the model generates two documented empirical regularities concerning the impact of monetary shocks on the distribution of prices. More specifically, the result is as follows.

\section{Result 1. The two price effects of monetary shocks.}

Monetary shocks generate wrong directional price changes and a temporary increase in the coefficient of variation of the cross-section of prices.

Discussion Figure 2 presents data from a computational experiment in which a positive monetary shock occurs at the end of the first time step. The figure presents the dynamics of all $10^{4}$ prices in the economy with a scale-free production network, with each price normalized to its pre-shock steady state value ${ }^{5}$. Figure 2 shows the dispersion of the cross-section of prices increases in response to a positive monetary shock as prices deviate away from each other reflected by the cone in the figure. As time moves forward the dispersion of cross section of prices decreases as reflected in the decreasing width of the cone region. Figure 3(a) presents the impulse response of the coefficient of variation of prices to positive monetary shocks. The coefficient of variation of prices temporarily increases on both balanced and scale-free production networks.

Figure 2 also shows some prices decrease in the response to the positive monetary shock as some prices are below one on the y-axis. In the first time step after a positive monetary shock, the firms who experience the initial injection of working capital increase demand for inputs and the suppliers of these inputs increase prices. Therefore, there are only price increases in the first time step after a positive monetary shock. The firms that receive the initial money injection gather more inputs at time step one and expand output (sold at time step two). These firms decrease prices at time step two if they do not meet a compensating increase in demand. In the third and following time steps, some firms decrease prices because they experience negative demand shocks or positive supply shocks due to the percolation of money through the production network. Note that a monetary shock which increases the price-level by $1 \%$ in the long run causes some prices

\footnotetext{
${ }^{5}$ The normalization of prices is consistent with VAR models that control for the initial distribution of prices (Lastrapes 2006).
} 
to decrease by $1-10 \%$ in the second, third, and fourth time step after the shock ${ }^{6}$. Figure $3(\mathrm{~b})$ presents the impulse response of wrong directional price change in response to positive monetary shocks. There are wrong directional price changes on both balanced and scale-free production networks. Furthermore, Figure 3 (b) $5-30 \%$ of the prices change in the wrong direction in the first five time steps after a monetary shock.

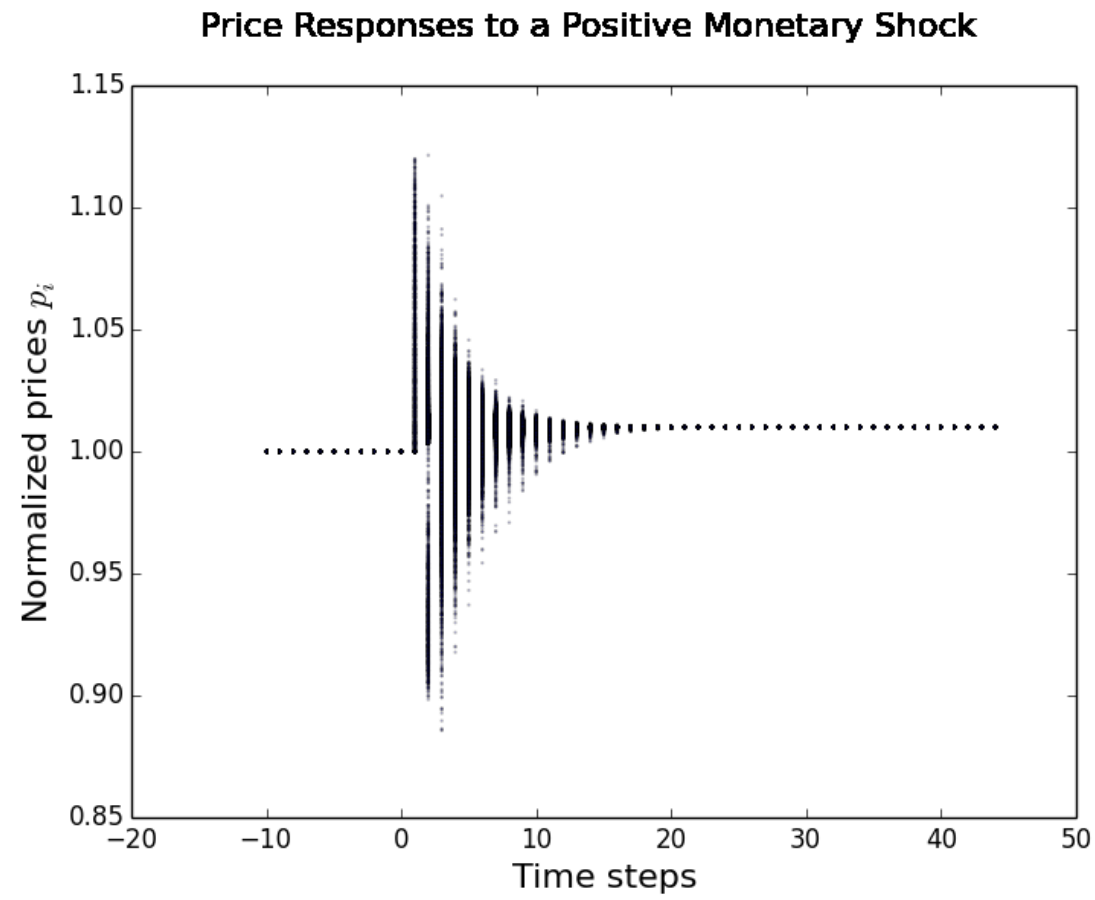

Figure 2: All price time series from one model run with a positive monetary shock. Parameters: $n=10^{4}, \alpha=0.1, g=0.1, d=2, s=0.01$.

\footnotetext{
${ }^{6}$ Within our model, monetary shocks generate significant variability in individual prices over time and not just in the cross-section of prices across firms. This is line with the empirical evidence documented by Domberger (1987) and Andrei, Herskovi \& Ledoit (2017). See Online Appendix for individual price time series.
} 


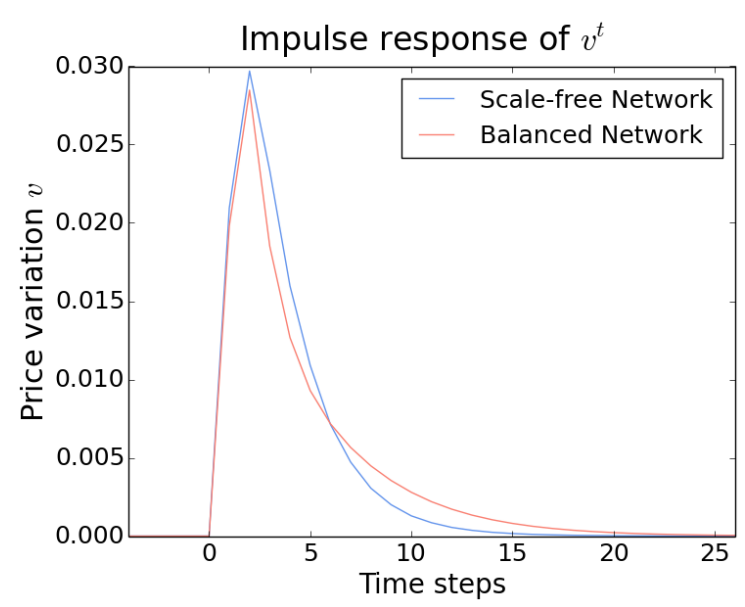

(a) $v^{t}$

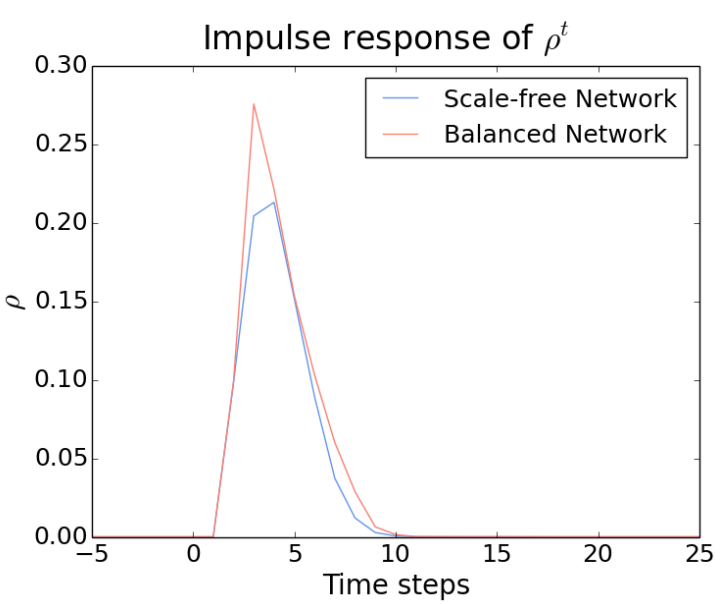

(b) $\rho^{t}$

Figure 3: Impulse response of price variation and wrong directional price change to a positive monetary shock on scale-free and balanced networks. The value for each time step is the mean value for the time step from 100 computational experiments. Parameters: $n=1000, \alpha=0.1$, $d=2, g=0.1$.

\subsection{Parameter variation and sensitivity analysis}

\subsubsection{Sensitivity to the size of the shock}

We first investigate the sensitivity of our results with respect to the size of the monetary shock, by which we mean the size of the monetary injection as a proportion of the total monetary mass in the economy. The principle result is as follows:

Result 2. Variation in the size of monetary shocks $s$.

The rise in variation of cross-section of prices increases with the size of monetary shocks. Wrong directional price change decreases with the size of monetary shocks.

Figure 4 presents $v$ and $\rho$ averaged over the first six time steps after a monetary shock, with variation in the size of monetary shocks. Figure 4(a) shows price variation $v$ increases with the size of monetary shocks. The greater the size of a monetary shock, the greater the temporary shifts in demand and supply encountered by firms as money percolates through buyer-seller linkages. With perfectly homogeneous shocks (an equiproportional increase in the working capital of all firms and the wealth of the household), $v$ would not increase with the size of the shocks because all prices would move in unison in response to the shocks though their movements may be large. Larger size shocks generate larger increases in $v$ because heterogeneous shocks percolate from one firm to another generating sequential and differential deviations in prices from each other. Figure 4(b) shows wrong directional price change $\rho$ decreases with an increase in the size of positive monetary shocks. This is because greater money injections generate greater positive demand shocks for the firms and therefore fewer firms decrease prices. 


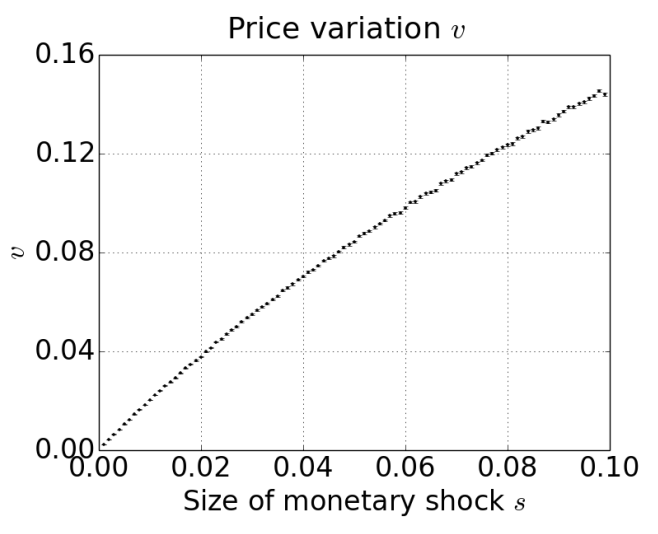

(a) $v$

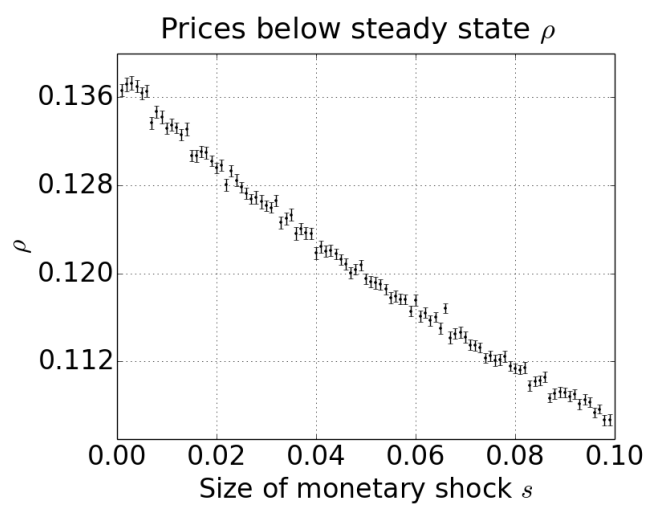

(b) $v^{t}$

Figure 4: Short run price response to positive monetary shocks of different sizes. Parameters: $n=1000, \alpha=0.1, g=0.1, d=2$. Positive monetary shocks range from 0.01 to 0.1 with increments of 0.001 , with 100 experiments for each size of shock.

\subsubsection{Sensitivity to the homogeneity of the shock}

Here we investigate the sensitivity of our results to the homogeneity of the shock, by which we mean the proportion of firms initially affected by a monetary shock. The principle result is as follows:

\section{Result 3. Variation in the homogeneity of monetary shocks $g$.}

The rise in variation of cross-section of prices decreases with the homogeneity of monetary shocks. Wrong directional price change has a non-monotonic relation with the homogeneity of monetary shocks.

Figure 5 presents $v$ and $\rho$ averaged over the first six time steps after a monetary shock, with variation in the homogeneity of monetary shocks. Figure 5(a) shows price variation $v$ decreases with the homogeneity of the monetary shock. As the shock becomes more homogeneous, the initial money injection is spread over a greater proportion of firms, which in turn causes prices to move more in tandem with one another. In the limit, if the initial monetary shock is equiproportionally distributed among all firms and the household, all prices change instantaneously and equiproportionally to the monetary shock and there is no increase in price variation.

Figure 5(b) shows for sufficiently low homogeneity of monetary shock, a strictly positive proportion of prices are below steady state in response to a positive monetary shock. However, when the homogeneity of monetary shock is sufficiently high, the proportion of prices that decrease below steady state in response to a positive monetary shock goes to zero. Figure 5(b) shows the relation between homogeneity and wrong directional price change $\rho$ is non-monotonic. The cause of the non-monotonic relation is as follows. Let $F$ denote the set of firms which receive the initial money injection and $S$ denote the set of firms which supply inputs to firms in set $F$. Wrong directional price change is generated by the firms that gather more inputs (and expand output) at one time step but do not experience a compensating increase in demand at the consequent time step. In the first time step after a positive monetary shock, firms in set $F$ gather a greater share of resources by bidding them away from competing users of the inputs. In the second time step 
after the shock, firms in set $F$ expand output and consequently decrease price if they do not face a compensating increase in demand. Firms in set $S$ follow with a one step time lag. Firms in set $S$ receive new money at time step one through an increase in demand for inputs from firms in set $F$. Firms in set $S$ purchase a greater share of inputs (by outbidding competing users) and consequently expand output at time step two. These firms decrease price at time step three if they do not encounter a compensating increase in demand. The suppliers of inputs to firms in set $S$ follow with a two step time lag, and so forth for other firms in the economy.

With low homogeneity few firms experience (and pass on) the initial money injection: set $F$ is small and therefore set $S$ tends to be small. Therefore, with low homogeneity few firms are able to gather more inputs and consequently decrease prices (at the consecutive time step) simply because few firms experience inflows of money at the early time steps. With high homogeneity, though many firms experience inflows of money at the early time steps, not many of them are able to gather more inputs by outbidding competing users of inputs because the competitors too experience inflows of new money. Therefore, with high homogeneity few firms are able to gather more inputs and consequently decrease prices (at the consecutive time step). Maximum wrong directional price change therefore occurs when homogeneity is neither too low, nor too high, when sufficiently large number of firms experience the initial money inflows but not enough of their competitors experience similar inflows.

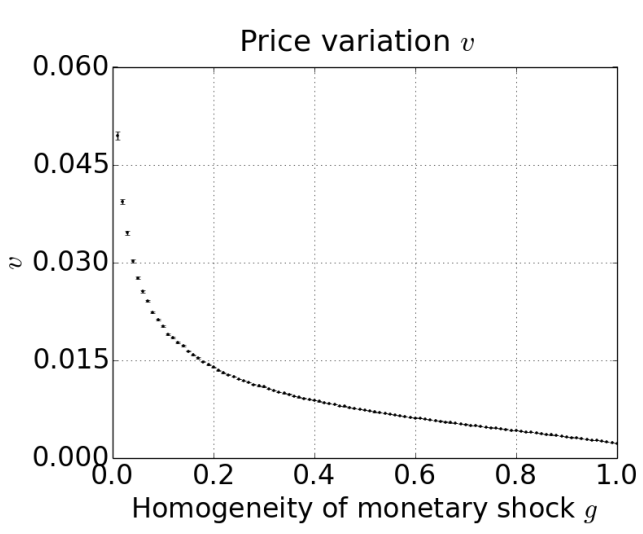

(a) $v$

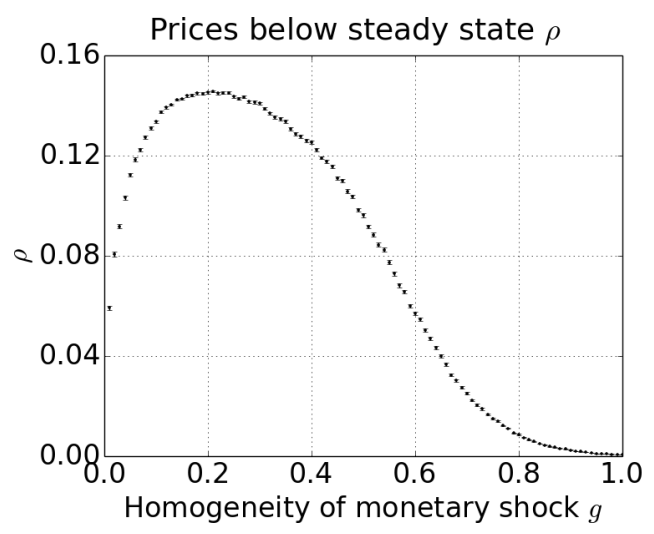

(b) $v^{t}$

Figure 5: Short run price responses to a positive monetary shock with different homogeneity of the shock. Parameters: $n=1000, \alpha=0.1, g=0.1, d=2$. Homogeneity of monetary shocks range from 0.01 to 1.0 with increments of 0.001 , with 100 experiments for each value of homogeneity.

\subsubsection{Sensitivity with joint variation in size and homogeneity of monetary shock}

Here we investigate the sensitivity of price variation $v$ and wrong directional price changes $\rho$ with joint variation in the size $s$ and homogeneity $g$ of monetary shocks. Figures $6(\mathrm{a})$ and $6(\mathrm{~b})$ are heatmaps of the values of $v$ and $\rho$, with the x-axis presenting values of size $s$ and the $y$-axis presenting values of homogeneity $g$. Figure $6(\mathrm{a})$ shows that the lower the homogeneity and the greater the size of monetary shocks, the greater the responsiveness of price variation. Figure 6 (b) shows that while wrong directional price changes decrease with the size of the monetary shock (as in Figure 4(b)), wrong directional price changes have a non-monotonic relation with 
the homogeneity of monetary shock (as in Figure 5(b)). Overall, the results from joint variations in parameter pairs are consistent with the inferences drawn from variations in single parameters. The monotonic relation between size $s$ and wrong directional price change $\rho$ holds for a range of values of homogeneity $g$, similarly the non-monotonic relation between homogeneity $g$ and wrong directional price change $\rho$ holds for a range of values of size $s$. Therefore, the joint-parameter variations show that the inferences drawn from single parameter variations are not limited to particularly values of other parameters.

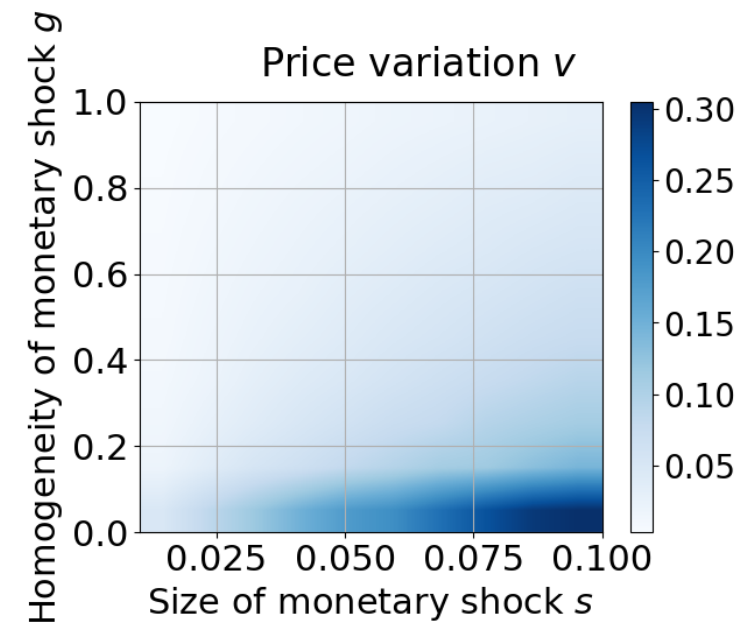

(a) $v$

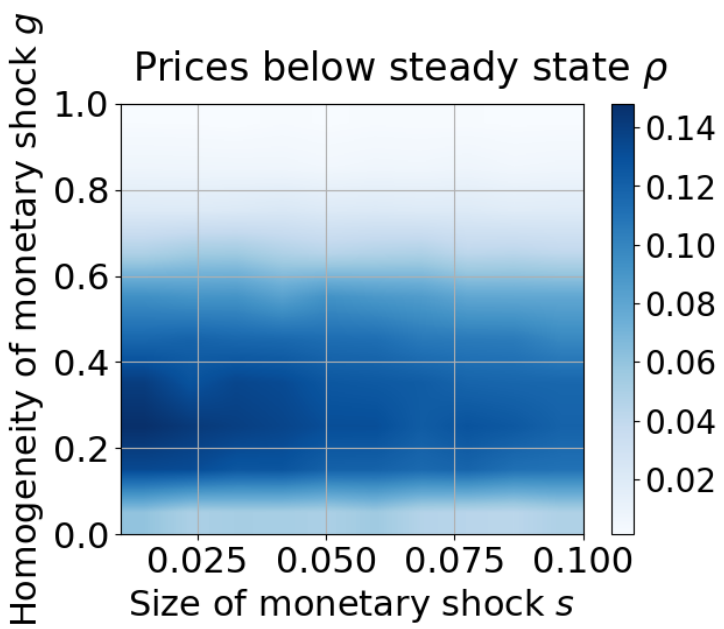

(b) $\rho$

Figure 6: Short run price responses to a positive monetary shock with different size and homogeneity of the shock. Parameters: $n=1000, \alpha=0.1, d=2$. Size of monetary shock ranges from 0 to 0.1 with increments of 0.01 , homogeneity of monetary shocks range from 0.01 to 1.0 with increments of 0.01 , with 5 experiments for each combination of size $s$ and homogeneity $h$.

\subsubsection{Sensitivity with respect to network structure}

Here we investigate how structural properties of the economy affect the propagation of monetary shocks by considering the sensitivity of the dynamics to the mean degree of the input-output network. The principle result is as follows:

Result 4. Variation in the mean degree of the production network.

The rise in variation of cross-section of prices decreases with the mean degree of the production network. Wrong directional price change decreases with the mean degree of the production network.

Figure 7 presents $v$ and $\rho$ averaged over the first six time steps after a monetary shock, with variation in the mean degree of the (scale-free) production network. Figure $7(\mathrm{a})$ shows price variation $v$ in response to a positive monetary shock decreases with the mean degree of the scale-free production network. As the mean degree of the production network increases, so does the connectivity between firms and the connections of the largest firms in the economy, therefore the shock itself spreads more uniformly across the production network. This means as the mean 
degree of the production network increases, prices move more in tandem with each other, thereby generating less variation in price responses to monetary shocks.

Figure 7 (b) shows wrong directional price change is negatively related to the mean degree of the production network. Note that within our model it is the positive supply shocks and the negative demand shocks generated by a positive monetary shock which create wrong directional price changes. Greater connectivity homogenizes a monetary shock by dispersing it among many firms, and thereby decreases the frequency and the size of positive supply shocks and negative demand shocks which follow from a positive monetary shock.

The result that the price effects of monetary shocks decrease with the mean degree of the production network is significant from the point of view of short term and long term changes in the production network. With respect to short term dynamics of production networks, using US data on firm buyer-seller networks Taschereau-Dumouchel (2018) reports that periods of low economic activity are associated with fewer well connected producers. He identifies certain theoretical mechanisms associated with the spread of idiosyncratic productivity shocks which generate the relation between production network connectivity and level of economic activity. In so far as well connected firms homogenise monetary shocks by spreading it among many suppliers of inputs, fewer well connected firms means the percolation of new money in the network takes more time thereby generating greater price effects. Our model coupled with Taschereau-Dumouchel's (2018) work suggests periods of low economic activity will be associated with greater price effects of monetary shocks. With respect to long term dynamics of production networks, Acemoglu \& Azar (2017) argue richer nations have "denser" production network. They identify certain theoretical mechanisms associated with the adoption of technology that generates denser network connections with economic growth. Xu-Hua, Chen \& Chen (2013) shows that density in scale-free network corresponds to mean degree. Our model coupled with Acemoglu \& Azar's (2017) empirical work suggests the price effects of monetary shocks will decrease with economic growth.

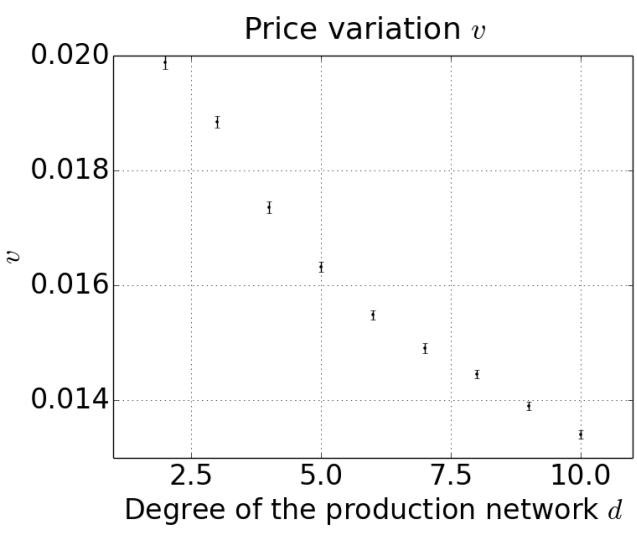

(a) $v$

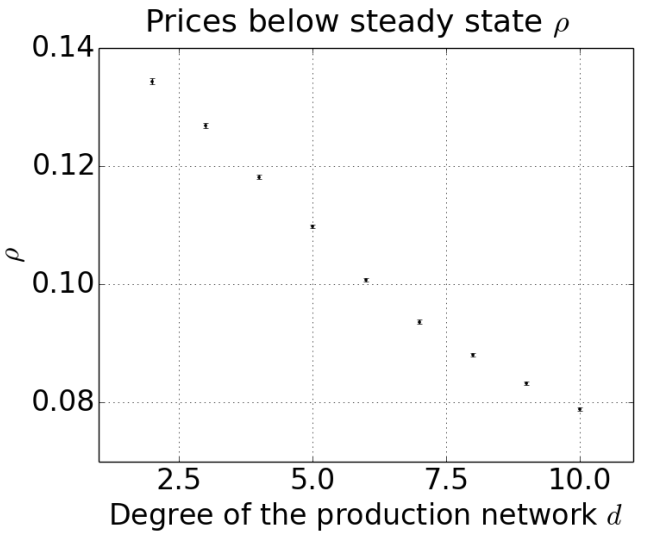

(b) $v^{t}$

Figure 7: Short run price responses to a positive monetary shock with different mean degree of scale-free production network $d$. Parameters: $n=1000, \alpha=0.25, g=0.1, s=0.01$. Mean degree of scale-free production networks range from 1 to 10 with increments of 1 , with 100 experiments for each value of mean degree. 


\subsection{Generalized monetary shocks}

\subsubsection{The specification of monetary shocks}

So far we studied a system in which the initial impact of a monetary shock falls upon a subset of firms. In this section, we report results from computational experiments in which the initial impact of a monetary shock falls upon all agents albeit differentially. The differential impact of monetary shocks is captured by a diversity parameter $\theta$. Namely, let $\lambda_{i}=\frac{w_{i}}{M}$ denote the ratio of agent $i$ 's nominal money holding to the stock of money in the economy. $\Delta M$ denotes the size of a monetary shock and $\Delta w_{i}$ denotes the change in firm $i^{\prime} s$ working capital (or the households wealth) due to the initial impact of a monetary shock. We consider the change in agent $i^{\prime} s$ money holdings due to the initial impact of a monetary shock is given by $\Delta w_{i}=z_{i}\left(\lambda_{i}+\epsilon_{i}\right) \Delta M$, where $\epsilon_{i}$ is drawn from an uniform distribution is $\left[0, \frac{\theta}{1+n}\right]$ and $z_{i}=\frac{1}{1+\sum_{i=0}^{n} \epsilon_{i}}$ is a normalization term. Note that a monetary shock is equiproportional if $\Delta w_{i}=\lambda_{i} \Delta M$ for all agents $i$. Thus the parameter $\theta$ measures the extent to which the monetary shock experienced by each firm differs from the aggregate measure of monetary shock. In some senses, $\theta$ represents the wide variety of differences among firms including their liquidity positions which influence the initial impact of a monetary shock on different firms, as shown by the empirical literature on the impact of monetary shocks (Gertler \& Gilchrist 1994, lyer et al. 2013, Carbó-Valverde, Rodríguez-Fernández \& Udell 2016).

\subsubsection{Further impacts of network structure}

This specification of monetary shocks further highlights the role of the network structure and of the heterogeneity of shocks on the dynamics of prices. The principle result is as follows:

Result 5. The topology of the production network matters when the initial impact of monetary shocks is upon all agents.

The rise in variation of cross-section of prices is greater on scale-free network than balanced network. There are no wrong directional price changes on balanced network for $\theta \in(0,1)$.

Figure 8(a) shows $v$ temporarily increases in response to positive monetary shocks. Figure 8(b) shows there are wrong directional price changes on scale-free network. The basic results of our model do not depend on the initial impact of monetary shocks being experienced by a subset of agents, the two price effects of monetary shocks occur even when the initial impact of a shock is upon all agents. This is simply because the non-equiproportional initial impact of a positive monetary shock on all agents generates out-of-equilibrium monetary flows, which in turn cause positive supply shocks and negative demand shocks, and consequently price decreases.

In the previous experimental setting when the initial impact of monetary shocks was upon a subset of firms, scale-free and balanced network exhibited comparable responses of price variation $v$ and wrong directional price change $\rho$ (see Figure 3). Figure 8(a) shows the temporary increase in $v$ is greater on scale-free network than balanced network. Figure 8 (b) shows there are wrong directional price changes on scale-free network but not on balanced network ${ }^{7}$. The specification of monetary shocks interacts with the topology of the production network to generate the price effects of monetary shocks. The imbalances (or irregularity) in the connections among firms aggravates

\footnotetext{
${ }^{7}$ In experiments not reported here, we see small wrong directional price changes on balanced network for $\theta>2$.
} 
small differences in the initial impact of monetary shocks and thereby generates considerable out-of-equilibrium money flows on scale-free networks. The topology of the balanced network on the other hand dampens small differences in the initial impact of monetary shocks.

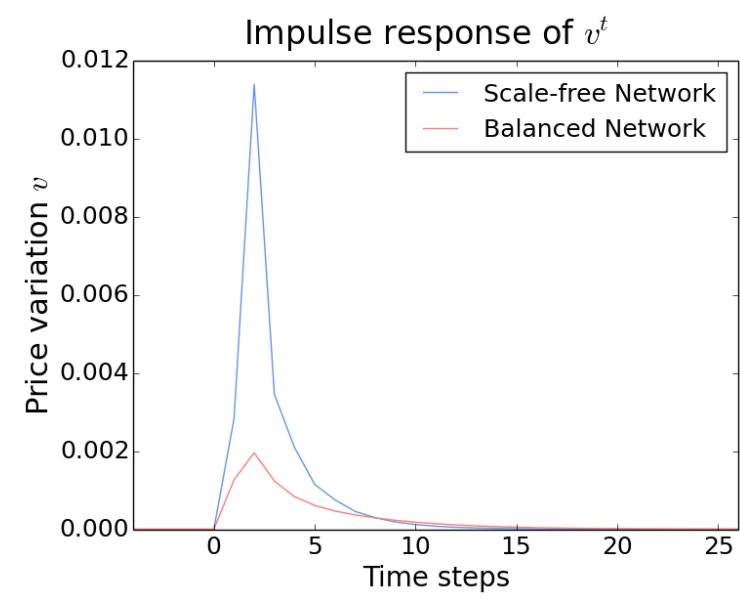

(a) $v^{t}$

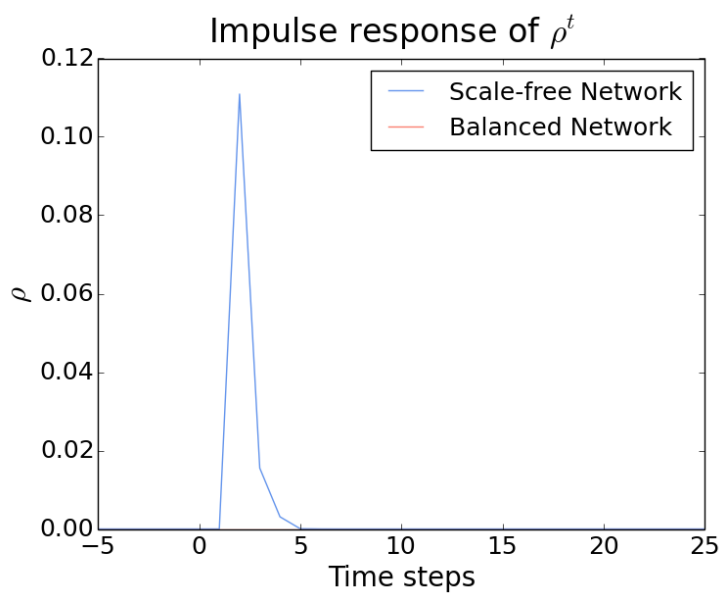

(b) $\rho^{t}$

Figure 8: Impulse response of price variation and wrong directional price change to a positive monetary shock on scale-free and balanced networks. The value for each time step is the mean value for the time step from 100 computational experiments. Parameters: $n=1000, \alpha=0.1$, $d=2, s=0.01$. These results pertain to the setting in which the initial impact of monetary shocks falls upon all agents albeit differentially.

\section{Concluding thoughts}

We have presented an analysis of the impact of monetary shocks on the distribution of prices using a simple model of out-of-equilibrium dynamics in a network economy. Despite its simplicity our model robustly reproduces the fact that price dispersion increases after a shock and the more puzzling fact that some prices decrease after a monetary shock. This second empirical phenomena was hitherto unexplained. The central message of the paper is that the puzzling wrong directional change in prices is essentially an out-of-equilibrium phenomena. It results from the heterogeneous propagation of monetary shocks through the production network of the economy, which is capable of generating large discrepancies between the supply a firm can provide (given relaxed financial constraints) and the realised demand it faces. Firms might have to temporarily adjust their prices downwards to correct this local disequilibrium.

Our analysis found that the topology of the production network influences the transmission of monetary shocks to real sector via its influence on prices. In the context of scale-free production networks, an increase in the mean degree of the production network decreases the proportion of prices that change in the wrong direction and the deviation of prices from their steady state values. Differences in the production network across nations is likely to generate differences in the price effects of monetary shocks. Similarly, changes in the production network over business cycle conditions is likely to generate changes in the impact of monetary shocks. Empirical evidence suggests production networks vary across nations and with business cycle conditions (Acemoglu \& 
Azar 2017, Taschereau-Dumouchel 2018). This is motivation for models of monetary policy to incorporate information on the structure and the cyclical dynamics of production networks.

Our model can be extended to generate hysteresis and permanent effects of monetary shocks on the economy. For instance, in the dynamic version of the model presented in Gualdi \& Mandel (2016), firms enter and exist the network based on relative prices. Within such a setting in so far as monetary shocks change relative prices, monetary shocks will influence firm entry and exist, and therefore the production network. Since the adjacency matrix of the production network influences equilibrium prices, monetary shocks by changing the adjacency matrix will generate permanent effects on the economy. Similarly, in the version of the model developed by Gualdi \& Mandel (2018) to study endogenous growth, innovation is influenced by relative prices. In this setting too, monetary shocks will have permanent effects on the economy by influencing firms' decisions on innovations and link formation.

Much of the analysis on why money matters has proceeded along two lines of thought. The first of which is the idea the monetary shocks affect real economic activity because of a misperception of the price-level (Lucas 1972, Cooley \& Hansen 1998, Collard \& Dellas 2010). The second is the idea that prices are slow to adjust and therefore quantities adjust in response to monetary shocks (Ball \& Mankiw 1994, Mankiw \& Reis 2002). This paper presented a third reason for why money matters, which is the relative price effects caused by the percolation of monetary shocks through the production network. Our approach to money differs fundamentally from monetary-misperception and sticky-price models because within our model the relative price effects of monetary shocks occur only in the out-of-equilibrium phase generated by a monetary shock. Monetary shocks, which are heterogeneous in their initial impact, disturb the steady state distribution of working capital among firms and thereby generate a 'reflux of flows' if you will. This reflux of money flows disturbs relative prices until the distribution of working capital reaches its new steady state. Monetary shocks have no relative price effects in equilibrium: the post-shock equilibrium differs from the pre-shock equilibrium only in the price-level.

As to whether the central role of disequilibrium in our model is a defect or a strength depends on one's view of the economic system. If like Milton Friedman (1961) one believes monetary shocks do indeed generate temporary disequilibrium, then out-of-equilibrium dynamics is not only a strength but a sacrosanct feature of our model. The idea that monetary shocks disturb equilibrium was common among the older generation of monetary theorists including Knut Wicksell, Ludwig Mises, and Friedrich Hayek. Nearly all modern work on network economy has however proceeded along equilibrium lines, at first concerning the propagation of real shocks and more recently on questions of money and finance (Dupor 1999, Horvath 2000, Acemoglu et al. 2012, Bigio \& La'O 2016). This paper is an early step in studying out-of-equilibrium dynamics of a network economy. Our investigation found that one aspect of relative price distortion due to monetary shocks-wrong directional changes in prices-occur only when the economy is far from equilibrium. Wrong directional price changes (the Mises Effect) vanishes as an economy gets to the neighborhood of equilibrium, and therefore cannot be studied - at least not in their full magnitude-by linearization of the equilibrium at epsilon distance from the steady state. 


\section{A Price dynamics of a three firm economy}

This section illustrates the price dynamics of our model using an economy with three firms and a representative household. The firms are connected to each other as depicted in Figure 9: the production network is a regular graph. The arrows in Figure 9 indicate the flow of goods, money flows in the opposite direction. A representative household (not in the figure) buys goods from and sells labor to all three firms. The household's preference is homogeneous $\left(\beta_{i}=\frac{1}{3} \forall i \in N\right)$ and therefore the household divides its expenditure equally among the three firms. Each firm spends $\alpha$ portion of its expenditure on labor and divides the rest equally among the other two firms $\left(a_{i j}=\frac{1}{2} \forall i, j \in N\right)$. Figure 10 shows the responses of prices to a positive monetary shock at time step indexed by zero. Figure 10(a) presents the case in which the initial impact of monetary shock is on Firm A. Figure 10(b) presents the case in which the initial impact of monetary shock is on Firm A and Firm B. Figure 10(c) presents the case in which the initial impact of monetary shock is on all three firms. Figure 10 (d) presents the case in which the initial impact of monetary shock is on all firms and the representative household.

Figure 10(a) shows price dynamics in response to a positive monetary shock to Firm $A$. When Firm $A$ receives a positive monetary shock, it increases the demand to Firm $B$ and therefore Firm $\mathrm{B}$ increases price at $t=1$. Money flows from Firm A to Firm B (and to the household). Firm A gathers more inputs and expands output at $t=1$ which is sold at $t=2$. Firm $A$ does not meet a compensating increase in demand at $t=2$, and therefore decreases its price. Firm $\mathrm{B}$ increases its demand at $t=2$ because it received new money from Firm $A$ at $t=1$. Firm $C$ experiences an increase in demand (as Firm B buys from Firm C) and therefore increases its price at $t=2$. Firm $\mathrm{B}$ decreases its price at $t=2$ because it faces less demand than it did at $t=1$ because Firm $A$ does not have as much money at $t=2$ as it did at $t=1$. There are bi-directional price changes at $t=2$ : Firm $A$ and Firm $B$ decrease prices, Firm $C$ increases its price. Firm A's price decrease is sufficiently large to take the price below its pre-shock steady state level.

Figure 10(b) shows price dynamics in response to a monetary shock to Firm A and Firm B: new money is equally divided among the two firms. At $t=1$, Firm $A$ increases demand towards Firm B and the household, Firm B increases demand towards Firm $C$ and the household. Firm B and Firm $C$ increase their prices equally at $t=1$ since both face an equal increase in demand albeit from different sources (Firm C from Firm B, and Firm B from Firm A). Firm A and Firm B are able to gather more inputs and consequently expand output at $t=1$ which is sold at $t=2$. At $t=2$ Firm $B$ decreases its price because Firm B does not meet a compensating increase in demand from Firm $A$ and the household, note that Firm $A$ has less money at $t=2$ than it did at $t=1$. Though Firm A expands output at $t=1$, it increases price at $t=2$ because it meet a more than proportional increase in demand. The reason Firm A meets a large increase in demand at $t=2$ is that new money goes from Firm B to Firm C which demands Firm A's goods, and from Firm $A$ and Firm $B$ to the household which also demands Firm A's goods. Firm $C$ also increases its price at $t=2$ due to both demand and supply side forces. Firm $C$ had to decrease its production at $t=1$ because Firm $A$ and Firm $B$ were able to gather a greater share of inputs with new money, and therefore Firm $C$ carried less output into $t=2$. On the other hand, part of the new money in the hands of Firm $\mathrm{A}$ was transferred to Firm $\mathrm{B}$ at $t=1$, and Firm $\mathrm{B}$ uses some of this money to demand goods from Firm $C$ at $t=2$. Yet again there are bi-directional price changes at $t=2$ : Firm $A$ and Firm $C$ increase prices, and Firm B decreases it price. Furthermore, Firm B's price decrease is sufficiently large to take the price below its pre-shock steady state level. 
Note that in this example, one of the firms which received new money at $t=0$ (namely Firm B) increases its price at $t=2$. Firm $\mathrm{B}$ was able to gather more inputs at $t=1$ and expand output: the positive monetary shock did generate a positive supply shock. Firm B entered $t=2$ with greater output due to the positive supply shock, however it experienced a positive demand shock which overwhelmed the positive supply shock, thereby generating an increase in price. Note also that Firm $C$ decreases its price (slightly) below its pre-shock level at $t=3$, though Firm $C$ did not receive the initial money injection. This is to illustrate not all firms which receive the initial money injection decrease prices below their pre-shock values, nor do firms which do not receive the initial money injection maintain prices above their pre-shock values.

Figure 10(c) shows price dynamics in response to a monetary shock to all firms: new money is equally divided among all firms. Since the production network is a regular graph all prices move equiproportional and in the same direction. At $t=1$ all prices increase as each firm faces an increase in demand from another firm, and therefore all firms increase prices. Furthermore, firms are able to gather a greater share of each other's output as an input into their own production process by bidding goods away from the household's consumption (as the household did not receive new money). Using the greater share of inputs gathered, firms expand output at $t=1$ and therefore decrease prices at $t=2$.

Figure 10(d) shows price dynamics in response to a monetary shock to all agents: new money is equiproportionally divided between the firms and the household. All price instantaneously jump their new equilibrium level, the monetary shock does not distort relative prices. There are no out-of-equilibrium dynamics when monetary shocks are perfectly homogeneous.

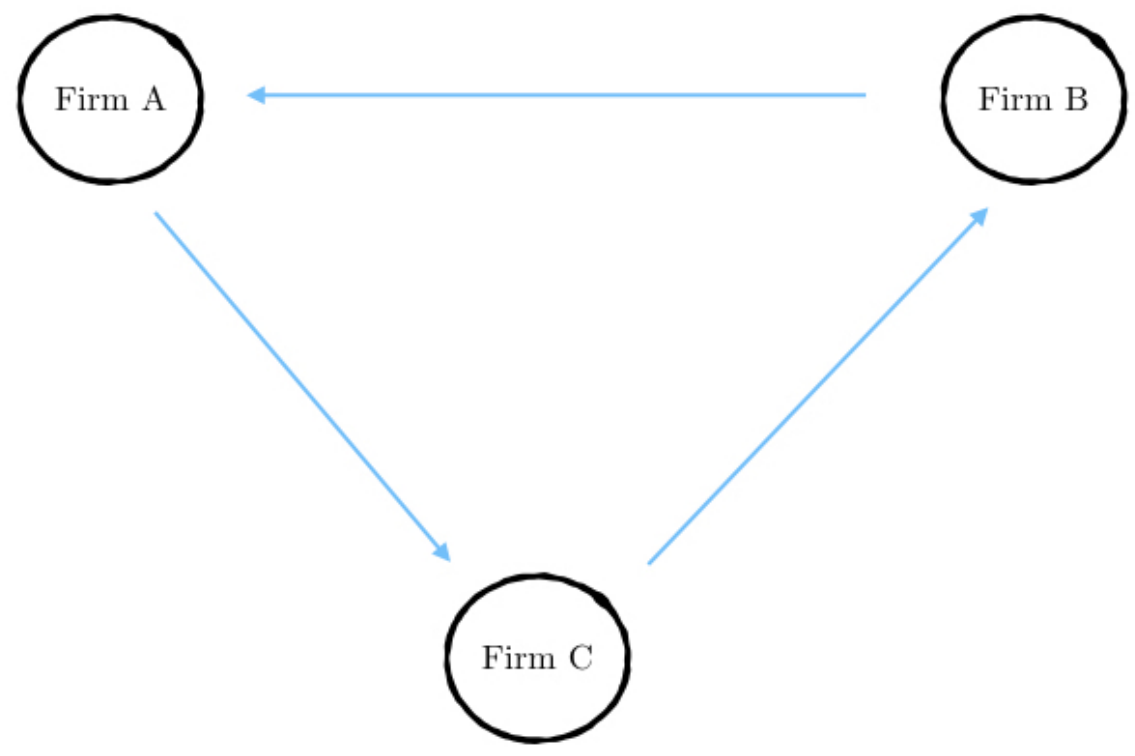

Figure 9: A three firm economy: direction of arrows indicates the flow of goods. 


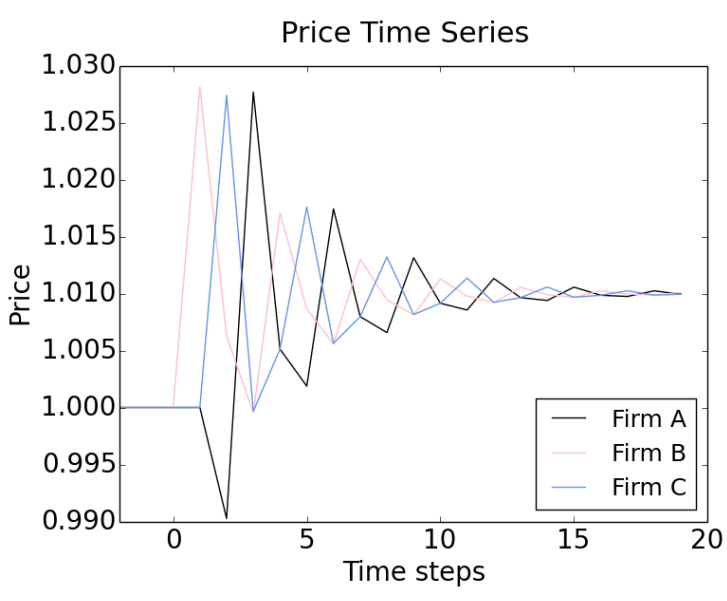

(a) Shock to Firm A

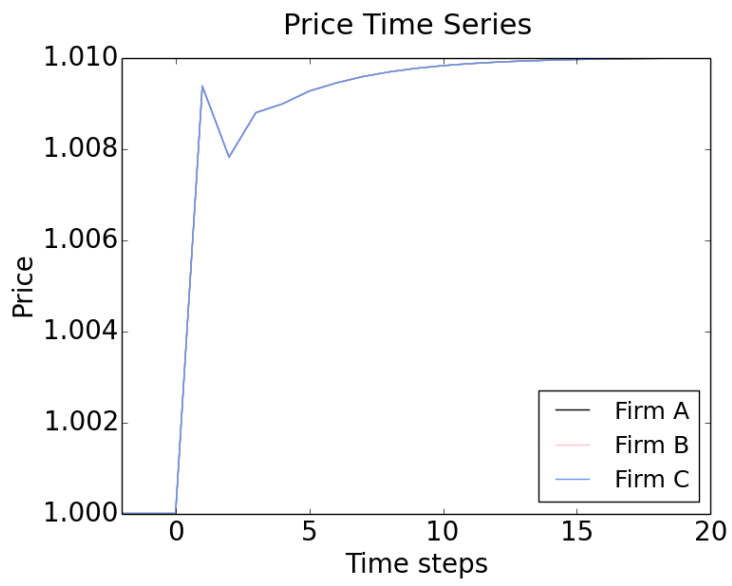

(c) Shock to all firms

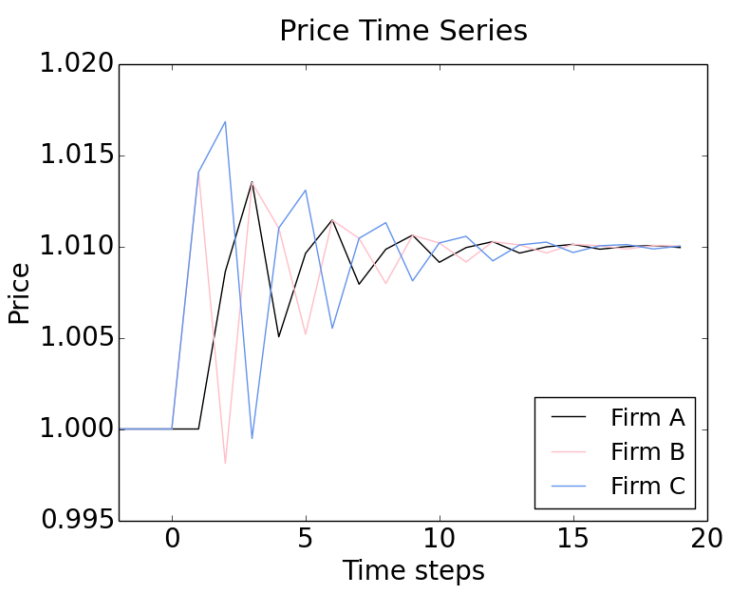

(b) Shock to Firm A and Firm B

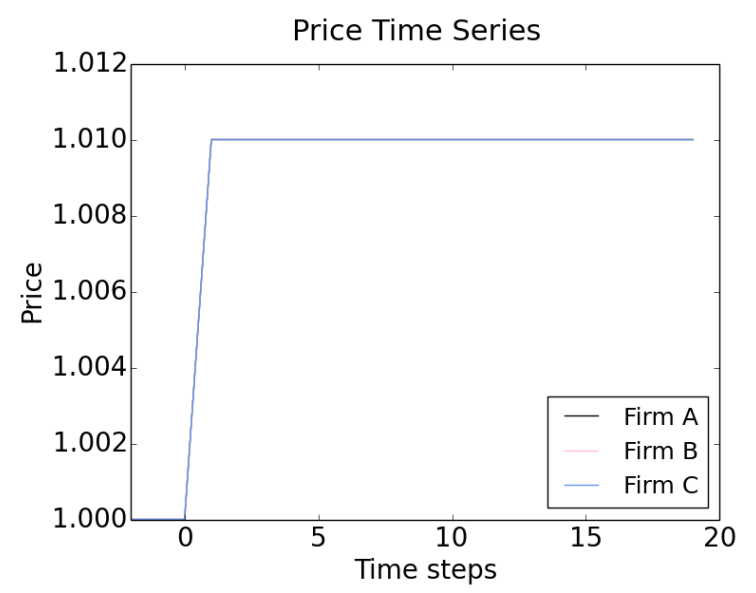

(d) Shock to all firms and the household

Figure 10: Price dynamics of a three firm economy with a positive monetary shock. Parameters: $n=3, \alpha=0.1, s=0.1$. 


\section{References}

Acemoglu, Daron, and Pablo D Azar. 2017. "Endogenous Production Networks." NBER Working Paper 24116.

Acemoglu, Daron, Vasco M Carvalho, Asuman Ozdaglar, and Alireza Tahbaz-Salehi. 2012. "The network origins of aggregate fluctuations." Econometrica, 80(5): 1977-2016.

Adrian, Tobias, and Hyun Song Shin. 2009. "Money, liquidity, and monetary policy." American Economic Review, 99(2): 600-605.

Andrei, Daniel, Bernard Herskovi, and Olivier Ledoit. 2017. "The redistributive effects of monetary policy." University of Zurich Department of Economics Working Paper 44.

Anthonisen, Niels. 2010. "Monetary shocks in a spatial overlapping generations model." Journal of Economic Dynamics and Control, 34: 2461-2484.

Arthur, W Brian. 2006. "Out-of-equilibrium economics and agent-based modeling." In Handbook of Computational Economics 2. , ed. Leigh Tesfatsion and Kenneth L. Judd, 1551-1564. Elsevier.

Atalay, Enghin, Ali Hortacsu, James Roberts, and Chad Syverson. 2011. "Network structure of production." Proceedings of the National Academy of Sciences, 108(13): 5199-5202.

Axtell, Robert L. 2000. "Why agents?: On the varied motivations for agent computing in the social sciences." Center on Social and Economic Dynamics, The Brookings Institution Technical Report 17.

Axtell, Robert L. 2001. "Zipf distribution of US firm sizes." Science, 293(5536): 1818-1820.

Axtell, Robert L. 2003. "Economics as distributed computation." In Meeting the Challenge of Social Problems via Agent-Based Simulation., ed. Terano, Takao, Hiroshi Deguchi and Keiki Takadama, 3-23.

Balke, Nathan S., and Mark A. Wynne. 2007. "The relative price effects of monetary shocks." Journal of Macroeconomics, 29(1): 19-36.

Ball, Laurence, and N Gregory Mankiw. 1994. "A sticky-price manifesto." In Carnegie-Rochester Conference Series on Public Policy. Vol. 41, 127-151. Elsevier.

Barabási, Albert-László, and Réka Albert. 1999. "Emergence of scaling in random networks." Science, 286(5439): 509-512.

Barro, Robert J, and Herschel I. Grossman. 1976. Money, Employment, and Inflation. Cambridge University Press.

Barrot, Jean-Noël, and Julien Sauvagnat. 2016. "Input specificity and the propagation of idiosyncratic shocks in production networks." The Quarterly Journal of Economics, 131(3): 1543-1592.

Baumeister, Christiane, Philip Liu, and Haroon Mumtaz. 2013. "Changes in the effects of monetary policy on disaggregate price dynamics." Journal of Economic Dynamics and Control, 37(3): 543-560.

Beck, Thorsten, Hans Degryse, Ralph De Haas, and Neeltje Van Horen. 2017. "When arm's length is too far. Relationship banking over the business cycle." Journal of Financial Economics, 127(1): 174-196.

Belton, Willie J, Richard J Cebula, and Usha Nair-Reichert. 2002. "Money and the dispersion of relative prices revisited." Applied Economics, 34(14): 1765-1773.

Bick, Alexander, and Dieter Nautz. 2008. "Inflation thresholds and relative price variability: evidence from US cities." International Journal of Central Banking, 4(3): 61-76.

Bigio, Saki, and Jennifer La'O. 2016. "Financial frictions in production networks." NBER Working Paper 22212.

Bikhchandani, Sushil, and Chi-fu Huang. 1993. "The economics of treasury securities markets." Journal of Economic Perspectives, 7(3): 117-134.

Bilo, Simon. 2018. "Lucas and Hume on monetary mon-neutrality: A tension between the logic and the technique of economics." Eastern Economic Journal, 44(3): 364-380. 
Bils, Mark, and Peter J Klenow. 2004. "Some evidence on the importance of sticky prices." Journal of Political Economy, 112(5): 947-985.

Bils, Mark, Peter J Klenow, and Oleksiy Kryvtsov. 2003. "Sticky prices and monetary policy shocks." Federal Reserve Bank of Minneapolis Quarterly Review, 27(1): 2-9.

Borrill, Paul L, and Leigh Tesfatsion. 2011. "Agent-based modeling: the right mathematics for the social sciences?" In The Elgar Companion to Recent Economic Methodology., ed. John B. Davis and D. Wade Hands, Chapter 11, 228-258. Edward Elgar Publishing.

Calvo, Guillermo A. 1983. "Staggered prices in a utility-maximizing framework." Journal of Monetary Economics, 12(3): 383-398.

Cantillon, Richard. 1755. Essai Sur La Nature Du Commerce En General. Reprint. Edited by Henry Higgs as "Essay on the Nature of Trade in General". New York: Kelley, 1964.

Carbó-Valverde, Santiago, Francisco Rodríguez-Fernández, and Gregory F Udell. 2016. "Trade credit, the financial crisis, and SME access to finance." Journal of Money, Credit and Banking, 48(1): 113-143.

Carvalho, Vasco M. 2014. "From micro to macro via production networks." The Journal of Economic Perspectives, 28(4): 23-47.

Carvalho, Vasco M, and Nico Voigtländer. 2014. "Input diffusion and the evolution of production networks." NBER Working Paper 20025.

Christiano, Lawrence, and Martin Eichenbaum. 1995. "Liquidity effects, monetary policy, and the business cycle." Journal of Monetary, Credit and Banking, 27(4): 1113-1136.

Clementi, Gian Luca, and Hugo A. Hopenhayn. 2006. "A theory of financing constraints and firm dynamics." The Quarterly Journal of Economics, 121(1): 229-265.

Coibion, Olivier, Yuriy Gorodnichenko, Lorenz Kueng, and John Silvia. 2017. "Innocent Bystanders? Monetary policy and inequality." Journal of Monetary Economics, 88: 70-89.

Collard, Fabrice, and Harris Dellas. 2010. "Monetary misperceptions, output, and inflation dynamics." Journal of Money, Credit and Banking, 42(2-3): 483-502.

Cooley, Thomas F, and Gary D Hansen. 1998. "The role of monetary shocks in equilibrium business cycle theory: Three examples." European Economic Review, 42(3-5): 605-617.

Delli Gatti, Domenico, Mauro Gallegati, Bruce Greenwald, Alberto Russo, and Joseph E Stiglitz. 2010. "The financial accelerator in an evolving credit network." Journal of Economic Dynamics and Control, 34(9): 1627-1650.

De Masi, Giulia, Yoshi Fujiwara, Mauro Gallegati, Bruce Greenwald, and Joseph E Stiglitz. 2011. "An analysis of the Japanese credit network." Evolutionary and Institutional Economics Review, 7(2): 209-232.

Deng, Xiaotie, Christos Papadimitriou, and Shmuel Safra. 2003. "On the complexity of price equilibria." Journal of Computer and System Sciences, 67(2): 311-324.

Domberger, Simon. 1987. "Relative price variability and inflation: a disaggregated analysis." Journal of Political Economy, 95(3): 547-566.

Dupor, First. 1999. "Aggregation and irrelevance in multi-sector models." Journal of Monetary Economics, 43(2): 391-409.

Friedman, Milton. 1961. "The lag in effect of monetary policy." Journal of Political Economy, 69(5): 447-466.

Friedman, Milton. 1977. "Nobel Lecture: Inflation and Unemployment." Journal of Political Economy, 83(3): 451472.

Gertler, Mark, and Simon Gilchrist. 1994. "Monetary policy, business cycles, and the behavior of small manufacturing firms." The Quarterly Journal of Economics, 109(2): 309-340.

Gigerenzer, Gerd, and Reinhard Selten. 2002. Bounded rationality: The adaptive toolbox. MIT Press. 
Gigerenzer, Gerd, and Wolfgang Gaissmaier. 2011. "Heuristic decision making." The Annual Review of Psychology, 62: 451-482.

Gornemann, Nils, Keith Kuester, and Makoto Nakajima. 2012. "Monetary policy with heterogeneous agents." Federal Reserve Bank of Philadelphia Working Paper 12-21.

Greenwald, Bruce C., and Joseph E. Stiglitz. 1993. "Financial Market Imperfections and Business Cycles." The Quarterly Journal of Economics, 108(1): 77-114.

Gualdi, Stanislao, and Antoine Mandel. 2016. "On the emergence of scale-free production networks." Journal of Economic Dynamics and Control, 73: 61-77.

Gualdi, Stanislao, and Antoine Mandel. 2018. "Endogenous growth in production networks." Journal of Evolutionary Economics, 1-27.

Hammoudeh, Shawkat, Duc Khuong Nguyen, and Ricardo M Sousa. 2015. "US monetary policy and sectoral commodity prices." Journal of International Money and Finance, 57: 61-85.

Hayek, Friedrich A. 1945. "The use of knowledge in society." The American Economic Review, 35(4): 519-530.

Hayek, Friedrich A. 1964. "The theory of complex phenomena." In The Critical Approach to Science and Philosophy. , ed. Mario Bunge, 332-349. Routledge.

Hayek, Friedrich A. 1976. Denationalization of Money: An Analysis of the Theory and Practice of Concurrent Currencies. The Institute of Economic Affairs.

Holmstrom, Bengt, and Jean Tirole. 1997. "Financial intermediation, loanable funds, and the real sector." The Quarterly Journal of Economics, 112(3): 663-691.

Holtz-Eakin, Douglas, David Joulfaian, and Harvey S Rosen. 1994. "Sticking it out: Entrepreneurial survival and liquidity constraints." Journal of Political Economy, 102(1): 53-75.

Horvath, Michael. 2000. "Sectoral shocks and aggregate fluctuations." Journal of Monetary Economics, 45(1): 45.

lyer, Rajkamal, José-Luis Peydró, Samuel da Rocha-Lopes, and Antoinette Schoar. 2013. "Interbank liquidity crunch and the firm credit crunch: Evidence from the 2007-2009 crisis." The Review of Financial Studies, 27(1): 347-372.

Kashyap, Anil K, and Jeremy C Stein. 2000. "What do a million observations on banks say about the transmission of monetary policy?" American Economic Review, 90(3): 407-428.

Konno, Tomohiko. 2009. "Network structure of Japanese firms." Economics: The Open-Access, Open-Assessment E-Journal, 3: 1-13.

Korliras, Panayotis G. 1977. "Non-Tatonnement and Disequilibrium Adjustments in Macroeconomic Models." In Equilibrium and Disequilibrium in Economic Theory. 463-495. Springer.

Lastrapes, William D. 2006. "Inflation and the Distribution of Relative Prices: The Role of Productivity and Money Supply Shocks." Journal of Money, Credit and Banking, 38(8): 2159-2198.

Lucas, Robert E. 1972. "Expectations and the Neutrality of Money." Journal of Economic Theory, 4(2): 103-124.

Lucius, Meisser. 2017. "The code is the model." International Journal of Microsimulation, 10(3): 184-201.

Mankiw, N Gregory, and Ricardo Reis. 2002. "Sticky information versus sticky prices: a proposal to replace the New Keynesian Phillips curve." The Quarterly Journal of Economics, 117(4): 1295-1328.

Manova, Kalina. 2012. "Credit constraints, heterogeneous firms, and international trade." Review of Economic Studies, 80(2): 711-744.

Mises, Ludwig von. 1949. Human Action. Yale University Press.

Mises, Ludwig von. 1953. The Theory of Money and Credit. Yale University Press.

Muellbauer, John, and Richard Portes. 1978. "Macroeconomic models with quantity rationing." The Economic Journal, 88(352): 788-821. 
Norman, Alfred Lorn. 1994. "Computability, complexity and economics." Computational Economics, 7(1): 1-21.

Ozdagli, Ali, and Michael Weber. 2017. "Monetary policy through production networks: Evidence from the stock market." NBER Working Paper 23424.

Scarf, Herbert. 1973. "The Computation of Economic Equilibria." In Cowles Foundation Monograph No. 24. Yale University Press.

Schelling, Thomas C. 1969. "Models of segregation." The American Economic Review, 59(2): 488-493.

Sheshinski, Eytan, and Yoram Weiss. 1977. "Inflation and costs of price adjustment." The Review of Economic Studies, 44(2): 287-303.

Sims, Christopher A. 2003. "Implications of rational inattention." Journal of Monetary Economics, 50(3): 665-690.

Stiglitz, Joseph E. 1988. "Why financial structure matters." Journal of Economic Perspectives, 2(4): 121-126.

Taschereau-Dumouchel, Mathieu. 2018. "Cascades and Fluctuations in an Economy with an Endogenous Production Network." Working Paper.

Varian, Hal R. 1977. "Non-walrasian equilibria." Econometrica, 45(3): 573-590.

Wagner, Richard E. 2012. "A macro economy as an ecology of plans." Journal of Economic Behavior \& Organization, 82(2): 433-444.

White, Lawrence H. 1999. The Theory of Monetary Institutions. Wiley-Blackwell.

Williamson, Stephen D. 2008. "Monetary policy and distribution." Journal of Monetary Economics, 55(6): 10381053.

Xu-Hua, Yang, Guang Chen, and Sheng-Yong Chen. 2013. "The impact of connection density on scale-free distribution in random networks." Physica A-statistical Mechanics and Its Applications, 392(10): 2547-2554. 